\title{
ONLINE ONLY
}

\section{CLINICAL MEDICINE}

\section{Image Diagnosis: Knee Dislocation}

Adam Gordon; Minh Van Le, MD; Clifford Swap, MD

Perm J 2016 Winter;20(1):e107-e108

http://dx.doi.org/10.7812/TPP/15-054

\section{CASE REPORT}

A 66-year-old man with no significant medical history presented to the Emergency Department with a chief complaint of acute left knee pain. The patient was performing a water ski jump when he landed awkwardly onto his flexed left knee. On arrival to the Emergency Department, he was noted to have a deformity of the left knee and was in severe pain. Physical examination of the patient's knee revealed a large bony prominence along the medial aspect with tenting of the skin (Figure 1). Vital signs were normal and neurovascular exam was intact. The ankle exam was normal, and his calf was soft and nontender. Left knee radiograph (Figure 2) showed an acute lateral dislocation of the tibia relative to the femur. The white lines in Figure 2 show grossly misaligned distal femoral condyles in relation to the tibial plateau. For comparison, Figure 3 shows a normal knee radiograph with normal alignment of the medial and lateral aspects of the femoral condyles in relation to the tibial plateaus. In our patient, there was associated patella dislocation, which can be commonly seen in knee injuries. The Orthopedic Department was consulted emergently and attempted to perform a closed reduction using procedural sedation. The patella was reduced, but the femoral medial condyle could not be reduced because of soft tissue interposition in the joint. A computed tomography angiogram of the left lower extremity was performed to assess vascular integrity (Figure 4). The scan showed no vascular injury but did show a posterior fossa hematoma caused by the knee dislocation following the attempted closed reduction. The Orthopedic Department then

performed open surgical reduction with external fixation as definitive treatment, and the patient recovered uneventfully.

\section{DISCUSSION}

Femorotibial dislocation is an uncommon extremity injury, typically occuring in the setting of high-energy mechanisms such as motor vehicle collisions, falls from heights, and certain sports. ${ }^{1}$ However, femorotibial dislocations still need to be in the differential diagnosis with low-energy mechanisms. Recent epidemiologic studies have shown that up to $46 \%$ of dislocations are in the setting of low-energy mechanisms, particularly with overweight individuals and amateur athletes. ${ }^{2}$ Isolated patella dislocations do not involve dislocation of the distal femur and proximal tibia, and they occur in injuries with much lower impact. Patella dislocations result in limited morbidity because the underlying neurovascular structures typically

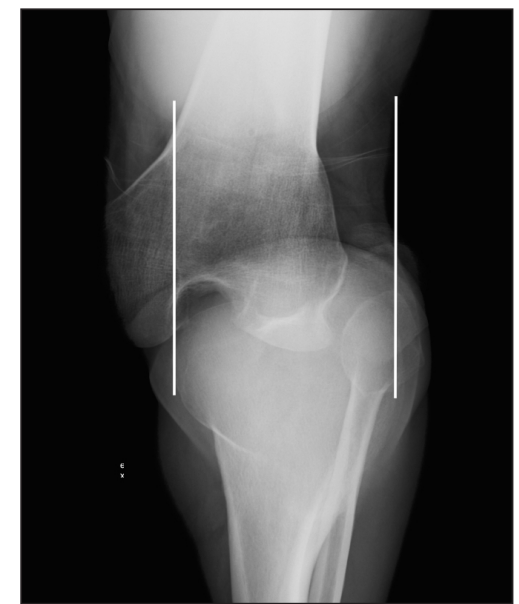

Figure 2. Anterior-posterior radiograph of the patient's left knee joint shows medial dislocation of the distal femur.

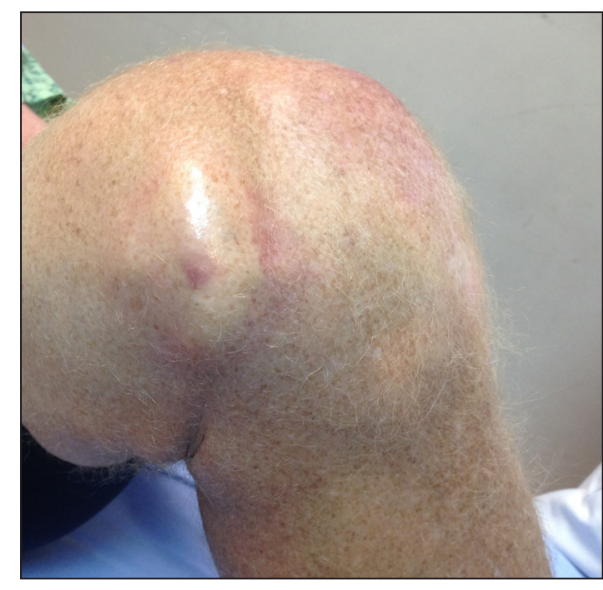

Figure 1. Physical examination of the left knee shows medial tenting of the skin because of medial femoral condyle knee dislocation.

remain uninjured. Less frequent, but of primary concern upon presentation, is concomitant vascular injury following knee dislocations. Upon our review of

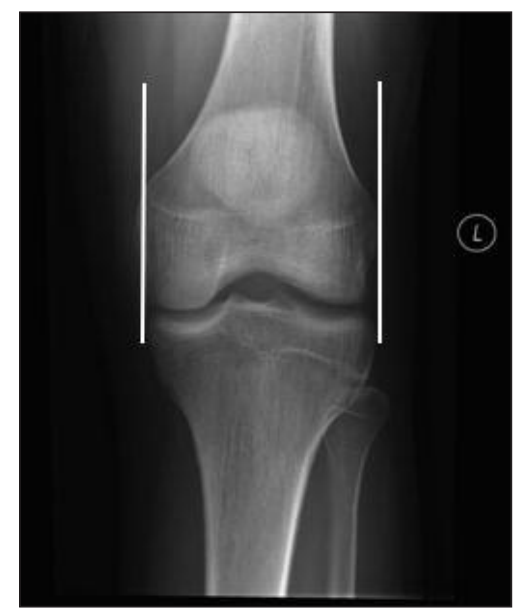

Figure 3. Comparison anterior-posterior radiograph of the left knee shows normal alignment of the knee joint. 


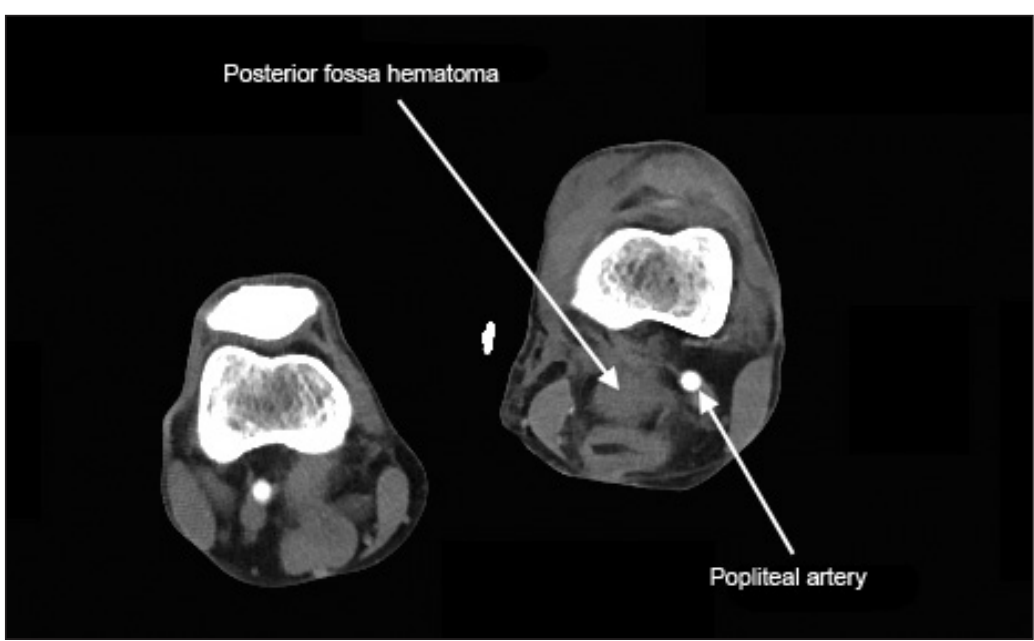

Figure 4. Computed tomography angiogram of the left and right knees showing the intact popliteal artery with posterior fossa hematoma and surrounding soft tissue swelling in the left knee.

the literature, we found that the frequency of vascular injury ranges from $7 \%$ to $32 \%$, the latter percentage being more representative of high-velocity mechanisms. ${ }^{3,4}$ If inaccurately diagnosed or managed, vascular compromise can result in total limb loss. ${ }^{4}$ In acute knee dislocations, examination should focus on assessment of the lower extremity distal pulses with the ankle-brachial index, followed by emergent anterior-posterior knee $\mathrm{x}$-rays and either arteriography or computed tomography angiography to assess vascular integrity. ${ }^{1,3}$ If the anklebrachial index is normal, some authors advocate for observation before angiography. ${ }^{5,6}$ Although angiography has historically been the gold standard for detection of vascular injuries following extremity trauma, recent evidence indicates that computed tomography angiography is less invasive, and a highly sensitive and specific alternative. ${ }^{7,8}$
The Orthopedic Department should be consulted immediately if clinical compromise of underlying structures is found on examination or imaging. Closed reduction should be attempted immediately under procedural sedation if any vascular compromise is suspected.

In our patient, reduction was attempted with successful reduction of the patella but unsuccessful reduction of the knee joint because of soft tissue interposition in the joint. The medial femoral condyle was not reducible, and the patient required operative reduction and fixation as definitive management. The pucker sign, which is the indentation of skin adjacent to the deformity and which can indicate entrapment of skin and soft tissue within the joint, and buttonholing, which occurs when the condyle herniates through the retinaculum, are signs of a possible irreducible knee dislocation. ${ }^{9-11}$

\section{References}

1. Perron AD, Brady WJ, Sing RF. Orthopedic pitfalls in the ED: vascular injury associated with knee dislocation. Am J Emerg Med 2001 Nov;19(7):583-8. DOI: http://dx.doi.org/10.1053/ ajem.2001.28333.

2. Sillanpää PJ, Kannus P, Niemi ST, Rolf C, Felländer-Tsai L, Mattila VM. Incidence of knee dislocation and concomitant vascular injury requiring surgery: a nationwide study. J Trauma Acute Care Surg 2014 Mar:76(3):715-9. DOI: http://dx.doi.org/10.1097/TA.0000000000000136.

3. Wascher DC. High-velocity knee dislocation with vascular injury. Treatment principles. Clin Sports Med 2000 Jul;19(3):457-77. DOI: http://dx.doi.org/ 10.1016/S0278-5919(05)70218-0.

4. Seroyer ST, Musahl V, Harner CD. Management of the acute knee dislocation: the Pittsburgh experience. Injury $2008 \mathrm{Jul} ; 39(7): 710-8$. DOI: http://dx.doi.org/10.1016/j.injury.2007.11.022.

5. Redmond JM, Levy BA, Dajani KA, Cass JR, Cole PA. Detecting vascular injury in lowerextremity orthopedic trauma: the role of CT angiography. Orthopedics 2008 Aug;31(8):761-7. DOI: http://dx.doi.org/10.3928/0147744720080801-27.

6. Nicandri GT, Chamberlain AM, Wahl CJ. Practical management of knee dislocations: a selective angiography protocol to detect limb-threatening vascular injuries. Clin J Sport Med 2009 Mar;19(2):125-9. DOI: http://dx.doi.org/10.1097/ JSM.0b013e31819cd37a.

7. Jeevannavar SS, Shettar CM. "Pucker sign" an indicator of irreducible knee dislocation. BMJ Case Rep 2013 Oct 4;2013. DOI: http://dx.doi. org/10.1136/bcr-2013-201279.

8. Peng PD, Spain DA, Tataria M, Hellinger JC, Rubin GD, Brundage SI. CT angiography effectively evaluates extremity vascular trauma. Am Surg 2008 Feb;74(2):103-7.

9. Stannard JP, Sheils TM, Lopez-Ben RR McGwin G Jr, Robinson JT, Volgas DA. Vascular injuries in knee dislocations: the role of physical examination in determining the need for arteriography. J Bone Joint Surg Am 2004 May;86-A(5):910-5.

10. Cınar M, Derincek A, Akpınar S. Irreducible dislocation of the knee joint: two-stage treatment. Acta Orthop Traumatol Turc 2011;45(4):280-3. DOI: http://dx.doi.org/10.3944/AOTT.2011.2377.

11. Kilicoglu O, Akman S, Demirhan M, Berkman M. Muscular buttonholing: an unusual cause of irreducible knee dislocation. Arthroscopy 2001 Jul;17(6):E22. DOI: http://dx.doi.org/10.1053/ jars.2001.9245. 